\title{
Discursive constructions of teacher in an educational technology journal
}

\author{
Jenny McDonald, Swee-Kin Loke \\ University of Otago
}

\begin{abstract}
The integration of technology with teaching and learning is a significant area of research in the educational technology field. Teachers play an instrumental role in technology integration, and many teacher-related factors have been identified that predict technology use and integration in educational settings. How teachers are represented in the educational technology literature (e.g., as caring, didactic or lazy) can potentially impact on how technology integration takes place. However, there is little research that specifically explores teacher representations. This paper seeks to address this gap and examines the discursive constructions of teacher in 846 papers from the Australasian Journal of Educational Technology (AJET). Using a corpus-based analysis, the multiple representations of teacher in AJET were investigated. The analyses revealed two mainstream representations of teacher: teachers are people on whom researchers impose obligations; and "teacherliness" is old and negative. This paper concludes with a discussion of the potential impact of such representations on technology integration and suggestions of more useful representations of teachers and their teaching.
\end{abstract}

\section{Introduction}

The field of educational technology is concerned with technology's influence on human learning (Clark, 1994; Kozma, 1994; Reiser, 2001). Because of this, the integration of technology in education is a significant area of research in the field. For example, the key purpose of the Australasian Journal of Educational Technology (AJET) is to promote "research and scholarship on the integration of technology in tertiary education" (ascilite, 2015) and a particular focus of the British Journal of Educational Technology is the "application of new information and communications technologies" (British Educational Research Association, 2015, ๆ 2) in education.

In most educational contexts, teachers play an instrumental role in technology integration. Research has identified many teacher-related factors that predict technology use in education. Such factors include teachers' openness to change (Vannatta \& Nancy, 2004), their morale (Baylor \& Ritchie, 2002) and pedagogical beliefs (Ertmer, Ottenbreit-Leftwich, Sadik, Sendurur, \& Sendurur, 2012). In practice, efforts in technology integration typically include professional development for teachers. For example, Victoria University's Digital Vision Strategy is supported by a range of workshops for teaching staff (Victoria University, 2016) and Deakin University's efforts to integrate their new cloud learning environment includes guides for teaching staff (Deakin University, 2016).

Given teachers’ instrumental role in technology integration, how teachers are represented can potentially impact on how technology integration takes place. For example, although Prensky's (2001) digital natives/digital immigrants model lacks empirical support (Kirschner \& van Merriënboer, 2013), it has nonetheless attracted widespread attention and is often used to make a case for technology integration in higher education (Kennedy, Judd, Churchward, Gray, \& Krause, 2008). A quick word count of all AJET papers from 2001 to 2014 reveals that the word Prensky appears in 49 out of 690 papers (7.1\%).

Prensky’s (2001) main argument is that young people (digital natives) use digital technologies differently from previous generations (digital immigrants), and that these differences warrant the integration of digital technologies in teaching in order to accommodate the skills and interests of digital natives. Prensky (2001) represents teachers who resist technology use as "lazy" (p. 6). In response, Bennett, Maton, and Kervin (2008) contend that such a representation has the potential to generate moral panic among teachers and to "alienate the very people being urged to change” (p. 783). In turn, alienating teachers can potentially run counter to the intention of transforming teaching practices: Clegg, Hudson, and Steel (2003) argue that the managerialist fashion in which e-learning was introduced in many universities resulted in "outward compliance combined with covert continuance of traditional practices" (p. 48). Hanson (2009) concurs that the pressure to incorporate e-learning in many universities has 
undermined the security of many academics' professional identity. Educational technology researchers who develop models of integration and/or work directly with teachers should exercise caution in how they represent teachers if they intend to transform teachers' teaching practices.

In what other ways are teachers and their teaching practices represented? Despite the potential impact of different representations of teacher, there is little research on how teachers are represented. Other studies have investigated the multiple meanings of teacher empowerment (Melenyzer, 1990), multicultural teacher education (Cochran-Smith, 2003), teacher development (ÅKerlind, 2003) and teaching in different cultures (Zhu, Valcke, \& Schellens, 2010). However, none were located that examined the meanings of teacher per se.

This paper aims to bridge the gap by studying the mainstream representations of teacher in a corpus of 846 AJET papers spanning 1991-2014. It is driven by two research questions:

(1) In what ways is teacher discursively constructed in AJET?

(2) What attitudes towards teacher emerge from AJET papers?

This research is timely for two reasons: first, the emergence of massive open online courses (MOOCs) in recent years has reignited the debate on the role and place of teachers. For example, some academics have taken the opportunity to reiterate the extreme view that any teacher who solely conveys information can and should be replaced by technology (Peck, 2013). Adopting a more moderate view, Bali (2014) contends that MOOC teachers need to become less teacher-centred (e.g., by relinquishing the authority of assessment to students) given that they cannot feasibly give personal attention to every student in MOOCs. The authors do not seek to support any of the above views, but simply to inform this current debate by providing a fuller understanding of how teacher has been represented in the educational technology literature.

Second, it is timely to examine the mainstream representations of teacher in a climate where teaching is arguably less valued. For at least the last 20 years, government or institutional policies have accentuated the relative value of university research over teaching (Cadez, Dimovski, \& Zaman Groff, 2015; Chalmers, 2011; Curtis \& Matthewman, 2005). Studies have shown that university research is often valued over teaching. For example, most academics perceive research output to be more influential than quality of teaching in leading to promotion and job security (Rowland, 1996; Young, 2006). Moreover, some institutions provide financial or time rewards for research performance but do not do the same for teaching performance (Cadez et al., 2015). The introduction of accountability mechanisms, such as the Performance-Based Research Fund in New Zealand in 2003, has arguably accentuated the researchteaching divide and further demoted the status of teaching (Curtis \& Matthewman, 2005). In New Zealand, the perceived effects of the lower status of teaching continue to be felt (Lewis, 2013).

In the next section, the potential impact of different representations on behaviours and practices is discussed in more depth. Then, the corpus-based method is described and justified before the study's findings are presented. The paper concludes with a discussion of the implications of the findings, notably suggestions of more useful representations of teachers and their teaching.

\section{Potential impact of different representations}

In their seminal work Metaphors We Live by, Lakoff and Johnson (1980) argued that how people think of something can shape the way they act. For example, arguments are often thought of as war (e.g., "Let him win the argument"; "You need to defend your argument"). Thinking of arguments as war can shape how people engage in arguments, for example, by planning to attack the weak points of someone else's argument. It is possible to think of arguments in alternative ways, for example, as a reasoning process. Consequently, one might engage in arguments as something that is collaboratively shaped with others on the basis of logic and reasoning, not as something to be won or lost against others.

Following Lakoff and Johnson (1980), several studies have explored the impact of different representations in higher education. For example, Prosser, Trigwell, and Taylor (1994) examined how teachers' teaching approaches are related to the different ways teachers think about teaching (e.g., as information transmission, as facilitating conceptual change). Similarly, Lee and Green (2009) examined 
how the different representations of a $\mathrm{PhD}$ supervisor-student relationship can shape supervision practices: a supervisor thinking of the $\mathrm{PhD}$ as a personal journey is likely to emphasise the student's ownership of the $\mathrm{PhD}$; a supervisor thinking of the supervisor-student relationship in terms of discipleship is likely to emphasise the asymmetrical power relation. More broadly, Harrison and Risler (2015) lament how representing students as consumers (who expect a comfortable learning experience) may have contributed to the practices of "lenient grading and keeping the classroom comfortably unchallenging" (p. 70). Drawing inspiration from the above studies, the authors contend that how teachers are represented can impact on how technology integration takes place.

\section{The AJET corpus}

The corpus for analysis consists of all 846 papers from AJET (5,473,923 words) spanning 1991 to 2014. AJET was chosen among other educational technology journals based on two criteria. First, the reputation of the journal: AJET is ranked 8th in Google Scholar rankings of educational technology journals. Second, to avoid potentially lengthy negotiations with publishers, the journal chosen should be open access; AJET is an open access journal. Initially, the authors intended to source a corpus from a range of journals, including subscription journals. However, library staff advised that permission from publishers would need to be sought before downloading large numbers of papers to avoid a potential breach of licence agreements between publishers and the authors' institution. The corpus was hence restricted to open access journals in order to progress this research in a timely manner. Most other reputable educational technology journals have only just started granting open access options (e.g., Computers \& Education since 2012 and Journal of Computer Assisted Learning since 2013).

It is important to point out that corpus-based studies are not restricted to journal articles and can involve any coherent collection of written or spoken text. McEnery, Xiao, and Tono (2006) define a corpus as "a collection of (1) machine readable (2) authentic texts (including transcripts of spoken data) which is (3) sampled to be (4) representative of a particular language or language variety" (p. 5). For example, Kovanović, Joksimović, Gašević, Siemens, and Hatala (2015) studied the representations of MOOCs in the public media. The authors chose to analyse journal papers because they seek to understand the views of educational technology researchers (not "outsiders" such as journalists or the general public). In this paper, by researchers, the authors mean researchers, academic developers, managers, and teachers who published their research work in AJET. The views of educational technology researchers, notably the academic developers who work directly with teachers, are likely to have a considerable impact on how technology integration takes place.

From a broader perspective, journals build the collective knowledge base of a particular research community (Schaffner, 1994). Journals can influence the views of their readers, and readers can reciprocally influence what journals publish and what researchers write about. In this way, the community jointly shapes its collective knowledge base. In this paper, the authors seek to understand how teacher is discursively constructed in the collective knowledge base of the Australasian educational technology community. This information can only be found through a corpus-based analysis and not by searching in a dictionary. The language used in educational technology journals is specific to the educational technology community (Hyland, 2004) and will provide unique insights into how teacher is represented by educational technology researchers.

In the next section, the process of corpus-based analysis will be described with the aim of explaining why it is an appropriate method to explore the research questions.

\section{Corpus-based analysis}

A corpus-based study is characterised by an analysis of the language of a corpus using automated and interactive quantitative and qualitative techniques (Biber, Conrad, \& Reppen, 1998). It is suitable for the purpose of this research for several reasons. First, a corpus-based analysis provides the most feasible way to study a large corpus of papers across a considerable time frame. Using computational methods allowed the authors to automate essential routine tasks such as identifying collocations (i.e., two or more words which commonly occur together); performing frequency counts of words, collocations, and phrases to identify typical representations; and creating concordances (i.e., keywords in their textual context; see 
Figure 1 for an example). These tasks facilitate the manual exploration of meaning in context, which can only be feasibly carried out using corpus-based techniques.

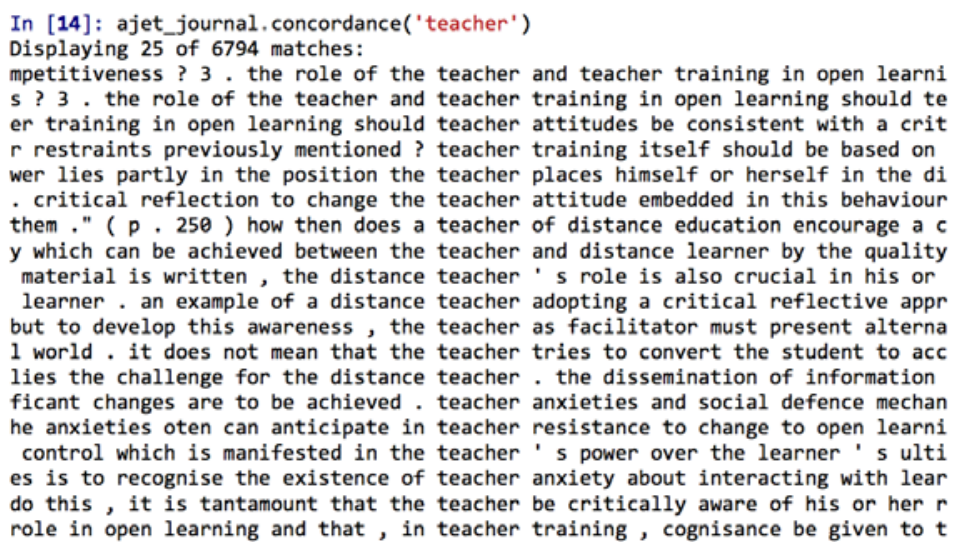

Figure 1. Example concordances for teacher as the keyword in context

Second, a corpus-based analysis allows the generation of valid and generalisable findings from a large corpus of papers. The more conventional methods of discourse analysis to examine language in use would require the selection of a small sample of papers, resulting in findings that may not generalise.

Third, the corpus-based method provides a fuller picture of the authors' research questions because it combines qualitative and quantitative analyses. It allows, and indeed requires, qualitative analysis to ensure "a functional interpretation of quantitative patterns" (Biber et al., 1998, p. 5).

Corpus-based methods have grown more popular for exploring language in use across a range of disciplines (Biber et al., 1998; McEnery \& Hardie, 2011). As computational techniques for working with text (or natural language processing) develop and become more accessible to a broad range of specialists, corpus studies have begun to appear in many disciplines including in educational research (e.g., Xiao \& McEnery, 2006).

Nevertheless, there are some criticisms and critics of corpus studies. Noam Chomsky notably said: “Corpus linguistics doesn't mean anything” (interviewed by Andor, 2004, p. 97), dismissing the collection of lots of data as largely unscientific. This view is arguably at an extreme of the methodological spectrum, ranging from introspection without evidence at one end to evidence without introspection at the other. Today, corpus linguistics methods are usefully employed across most areas of linguistics (McEnery \& Hardie, 2011) and require evidence and introspection in equal measure (Biber et al., 1998).

More practical concerns include issues relating to tools and the size and selection of the corpus for study (Louw \& Chateau, 2010). These issues will be addressed in the next section, in which the specific methods and tools that were used will be described in some detail. This level of detail is provided for two reasons: firstly, because there are few detailed descriptions of practical methods in the educational technology research literature for those who wish to follow an example; secondly, so that others may reproduce and hopefully improve upon the authors' approach. Obtaining and cleaning the corpus is described first, followed by the analysis of the corpus.

\section{Obtaining and cleaning the corpus}

In the case of AJET papers, it was reasonably straightforward to obtain the corpus because it consisted of well-structured web-based material. The structure of the AJET website was examined, and all papers from 1991 automatically downloaded using a Python script. At the time that the study was undertaken, issues of the journal from its inception in 1985 through to 1990 were available online but were structured differently. For the purposes of this research, 1991-2014 was a sufficient range: The corpus comprises 
more than 5 million tokens (words), which is of ample size compared with other scientific corpora (e.g., BAWE SciEngL1 sub-corpora range from 18,000 tokens to 427,000 tokens) (Louw \& Chateau, 2010).

After downloading each AJET article and converting to a text file using a command-line batch process and pdf-to-txt utility, each file was stripped of its header, footer and page information. This was essential in order to avoid skewing word frequency counts. For similar reasons, all references and keywords from the text files were also removed. This process was largely automated, again using a custom Python script, although changes to the AJET journal style through the years necessitated a small amount of manual intervention.

\section{Analysing the corpus}

Early explorations for many corpus studies begin with word frequency analyses, identifying words that co-occur, and inspecting concordances. There are many tools available for corpus exploration. The authors narrowed the options down to two candidates: AntConc (Anthony, 2014) and the Natural Language Toolkit - NLTK (Bird, Loper, \& Klein, 2009). When keyword frequencies between the tools were compared, either no difference or minor differences were found. The minor differences could easily be accounted for through variation in tokenisation procedures.

Tokenisation is the process of turning a string of text into a series of tokens where each word is a token. For example, "The cat's tail was lying in the sun." can be represented as a list of tokens: [the, cat, ', s, tail, was, lie, in, the, sun, .]. Two things are apparent from this example: punctuation and the possessive case are represented as separate tokens. Tokenisation can also be associated with the process of normalisation: unifying the text case; spell-checking; removing numbers, diacritical marks and lemmatisation (removing inflectional endings; e.g., lying => lie). The NLTK was chosen as it afforded far greater control and flexibility in terms of tokenisation and the possible types of analysis. However, the NLTK is a Python library and therefore requires some programming ability.

For the purposes of this research, the authors were initially interested in identifying all instances of teacher and teaching in the corpus. The corpus was hence normalised to all lower case in order that Teacher and teacher, for example, were treated as a single word. Synonyms and alternative forms of teacher(s) and teaching (e.g., instructor, lecturer) were also considered. However, the base frequency of these terms was low compared to teacher(s) and teaching. This study was therefore restricted to the terms most commonly found in the AJET corpus. Inflectional endings, diacritical marks and numbers were retained as these were likely to assist rather than detract from the corpus analysis in the context of this study (e.g., to distinguish between the person, teacher and the act of teaching). Standardised spellings were assumed given that the corpus is from a reputable research journal.

Since the discursive representations of teacher were of primary interest, the words with which teacher(s) and teaching commonly occur (otherwise known as collocates) were identified. In addition, the ways in which teacher(s) and teaching appeared in context with their collocates were inspected. In other words, a qualitative functional assessment of the language around teacher(s) and teaching was made. This assessment is important because the meaning of a word emerges from the word's textual context and not just the individual word. J. R. Firth notably coined the phrase: "You shall know a word by the company it keeps!” (Palmer, 1968, p. 179), which gives an apt introduction to the concepts of semantic prosody and semantic preference.

Semantic prosody refers to the idea of a word taking on positive or negative connotations because of its association with other words. Oster (2010) points to several classic examples of semantic prosody: the word utterly commonly combines with negative adjectives (e.g., devastated, fatuous, exhausted) and the verb cause with negative nouns like fear and alarm.

Semantic preference is the association between a word and the semantic field it is commonly found in. For example, it is likely that the word technology has a preference for the semantic field of utility (e.g., technology use, technology can). In comparison with semantic prosody, semantic preference does not indicate positive or negative connotations. These two concepts will be referred to in the Findings section. 


\section{Procedure for analysing the corpus}

Stopwords were removed from the corpus. Stopwords are essentially words that add little semantic information but occur commonly. They can skew frequency distributions and collocation discovery. Definite and indefinite articles (e.g., the, an), prepositions (e.g., on, off, from, to) and relative pronouns (e.g., which, that) are all examples of potential stopwords. However, the choice of stopwords can vary with context. A custom stopword list based on the standard NLTK stopwords was created, but with modal verbs (e.g., can, may, will, must) removed. Modal verbs express the speaker's attitude towards a particular action (Palmer, 2001). Since this research focuses on educational technology researchers' attitudes towards teacher, modals were included in the analysis.

The NLTK Bigram Collocation Finder was used to identify the top 30 collocates within 1 word to the left or right of teacher(s) and teaching. Bigrams are 2-word collocates (e.g., teachers-should, traditionalteaching). These bigrams were then ranked using the likelihood ratio metric, which is a measure of how much more likely a bigram is to occur than the base frequency of its component words suggests (refer to Manning \& Schütze (1999) for a detailed discussion of collocation discovery metrics). The likelihood ratio metric was chosen because it is relatively easy to interpret (see Findings section) and because it is particularly appropriate for sparse data (i.e., words or linguistic features that occur infrequently in a large sample space) (Manning \& Schütze, 1999).

From the list of top 30 bigrams, only bigrams that were directly relevant for this research were selected. The selection was made by scanning the concordances of the bigrams. For example, preservice-teacher was discarded because it was purely descriptive and did not reflect any particular attitude towards teacher. For some other bigrams that did reflect a particular attitude, the authors were unable to systematically distinguish the various meanings of the bigrams and decided to discard these bigrams. For example, in the case of teachers-can, the authors were unable to systematically distinguish between the meanings of ability (e.g., teachers can access the online video) and suggestion (e.g., some of the ways that teachers can translate different teaching approaches).

For the selected bigrams, concordances were produced in order to inspect what meanings each of the bigrams produced in context. An example of concordances is given in Figure 2. A simple extension to the NLTK concordance index class was written in order to produce concordances from the selected bigrams.

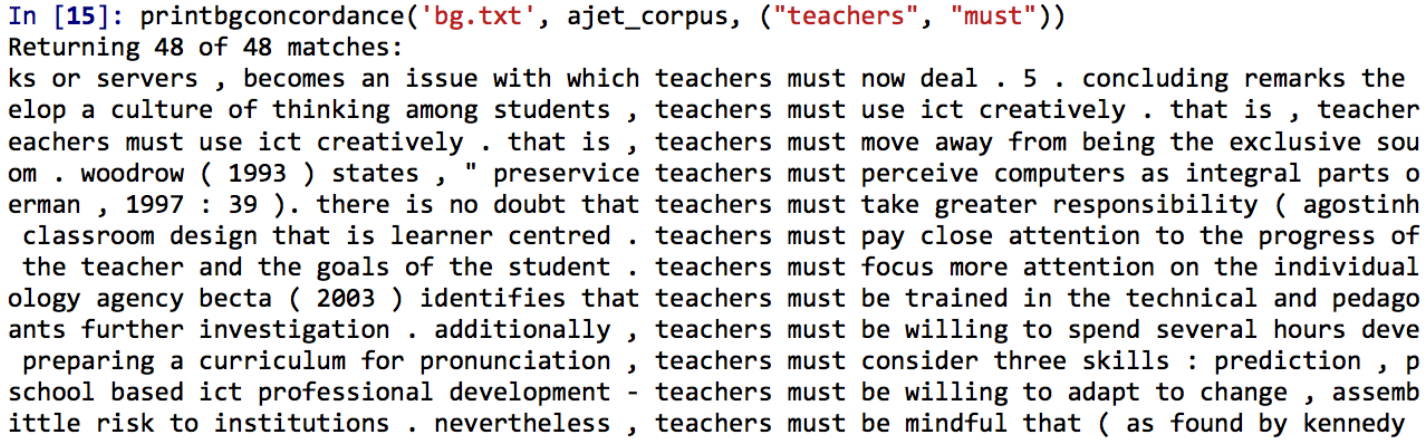

Figure 2. Example concordances for the bigram teachers-must

The authors independently reviewed and applied labels to all bigram concordances, and then met to negotiate the meanings of their labels and subsequently applied previously agreed labels to all bigram concordances. Table 1 provides examples of the labelling process for the bigram teachers-need. 
Table 1

Review and labelling of bigram teachers-need

\begin{tabular}{lll}
\hline Bigram in context & Rater $\mathbf{1}$ label & Rater $\mathbf{2}$ label \\
\hline $\begin{array}{l}\text { T. Parks and Pisapia (1994) suggest that teachers need } \\
\text { formal training in the following areas }\end{array}$ & requirement-help & requirement-help \\
$\begin{array}{l}\text { in excellent infrastructures and support, teachers need to } \\
\text { find ways of incorporating the uniq }\end{array}$ & $\begin{array}{l}\text { requirement- } \\
\text { competence }\end{array}$ & $\begin{array}{l}\text { requirement- } \\
\text { competence }\end{array}$ \\
$\begin{array}{l}\text { f pedagogical content knowledge posits that teachers need } \\
\text { to integrate their own knowledge of ma }\end{array}$ & $\begin{array}{l}\text { requirement- } \\
\text { competence }\end{array}$ & $\begin{array}{l}\text { requirement- } \\
\text { competence }\end{array}$ \\
\hline
\end{tabular}

Inter-rater reliability (IRR) scores were calculated for all bigram concordances (unweighted Cohen's kappa for two raters using nominal labels) (R Core Team, 2015). IRR assigns a score between 0 and 1 , where 0 is no agreement between raters greater than chance alone and 1 is complete agreement. The authors met to review all bigrams in context where kappa fell below a threshold of 0.41 , which indicates less than moderate agreement on the Landis and Koch (1977) benchmark. The labels and label meanings were adjusted where required, and each bigram in context relabelled and Cohen's kappa recalculated.

Upon examination of the labels, similar labels emerged from different bigrams (e.g., the bigrams teachercentred and teacher-directed had similar labels). The bigrams were clustered into two groups based on these similar labels.

Finally, the occurrence of all bigrams of interest over time was calculated. This was important for two reasons: It is possible that individual papers or groups of papers might influence the results of the study (e.g., a high occurrence of a particular bigram in a single paper); it is also interesting to see if there was diachronic variation, or variation over time, in how teacher(s) and teaching are represented in AJET.

\section{Findings}

Figure 3 provides a summary of our initial corpus exploration. From the total corpus of more than 5 million words of which 2,700,819 are content words (i.e., excluding stopwords), the top 10 most frequent words include students (count $=41,585$, rank $=1$ ), learning (count $=41,347$, rank $=2$ ), technology (count $=12,697$, rank $=6)$, online $($ count $=12,070$, rank $=8)$, teachers $($ count $=12,030$, rank $=9)$ and teaching (count $=11,884$, rank $=10$ ). Other words in the top 10 include use, have, student and can.

Across the 23 years of AJET included in our corpus, the frequency of the most frequent words tends to increase over time. This might partly be explained because there were more issues of AJET published per year by 2014 (six/year) than there were in 1991 (two/year), and more articles per issue at least between 2010 and 2013. However, there are likely other reasons: for example, the word online does not appear regularly until 1999, 10 years after the invention of the Word Wide Web (1989) but only 2 years after the learning management system company Blackboard was founded (1997). This word appears typically in the context of online learning and online discussion in the corpus. Another feature of the initial corpus exploration is that students, technology and teachers are identified as key protagonists in educational technology discourse. 


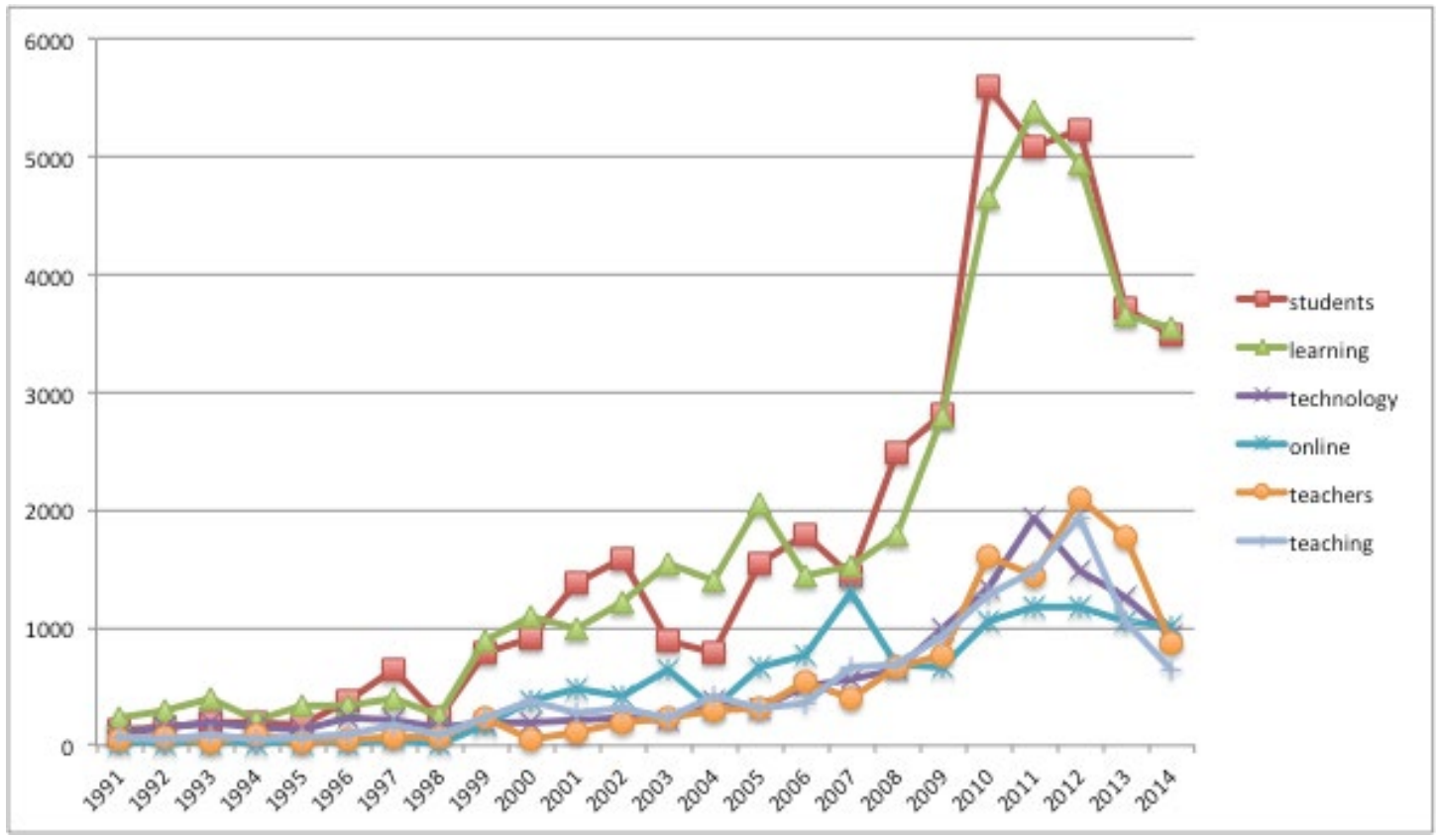

Figure 3. Distribution of relevant top content words from 1991 to 2014

Table 2 presents the top 30 bigrams of teachers. The top 30 bigrams of teacher and teaching are excluded here because of space limitation, but these are available online (http://bit.ly/1J5i9Tf). The bigrams are ranked according to their log likelihood. What this means is, for example, given the word should, the bigram teachers-should is $\mathrm{e} \wedge(323 \times 0.5)$ times more likely to occur in this corpus than the base frequency of teachers suggests. Base frequencies and bigram frequencies are provided for comparison in each case. The selected bigrams that are directly relevant for this study are highlighted.

Table 2

Top 30 bigrams of teachers

\section{Top Teachers Bigrams}

('service', 'teachers')

('preservice', 'teachers')

('student', 'teachers')

('beginning', 'teachers')

('preschool', 'teachers')

('prospective', 'teachers')

('science', 'teachers')

('mathematics',

'teachers')

('cfl', 'teachers')

('school', 'teachers')

('teachers', 'need')

('trainee', 'teachers')

('teachers', 'can')

('teachers', 'have')

('teachers', 'should')

('many', 'teachers')

('participating', 'teachers')

('practising', 'teachers')

('help', 'teachers')

('experienced',

'teachers')

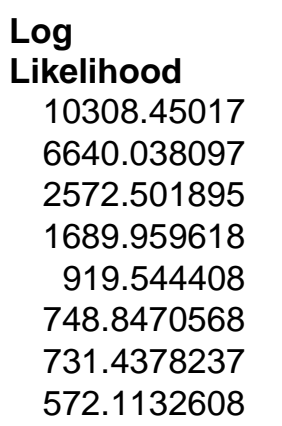

529.5208304

476.9350855

442.5724841

426.7322257

358.9655561

336.1092292

323.5596758

300.1824201

241.6369216

226.7094189

215.7901483

205.2177844

\begin{tabular}{|c|c|c|}
\hline $\begin{array}{l}\text { Freq } \\
\text { Word1 }\end{array}$ & $\begin{array}{l}\text { Freq } \\
\text { Word2 }\end{array}$ & $\begin{array}{l}\text { Freq } \\
\text { Bigram }\end{array}$ \\
\hline 1984 & 12030 & 1058 \\
\hline 680 & 12030 & 585 \\
\hline 13253 & 12030 & 605 \\
\hline 898 & 12030 & 21 \\
\hline 169 & 12030 & 9 \\
\hline 197 & 12030 & 8 \\
\hline 1894 & 12030 & 141 \\
\hline 919 & 12030 & 9 \\
\hline 345 & 12030 & 72 \\
\hline 5555 & 12030 & 14 \\
\hline 12030 & 4159 & $12 \varepsilon$ \\
\hline 99 & 12030 & 4 \\
\hline 12030 & 12245 & 17 \\
\hline 12030 & 13892 & $17 \varepsilon$ \\
\hline 12030 & 3855 & 10 \\
\hline 4143 & 12030 & 10 \\
\hline 596 & 12030 & 4 \\
\hline 113 & 12030 & 2 \\
\hline 2565 & 12030 & 68 \\
\hline 886 & 12030 & 4 \\
\hline
\end{tabular}




$\begin{array}{lrrrr}\text { ('cooperating', 'teachers') } & 201.8229113 & 40 & 12030 & 21 \\ \text { ('novice', 'teachers') } & 189.4916265 & 299 & 12030 & 32 \\ \text { ('university', 'teachers') } & 185.9844446 & 6773 & 12030 & 93 \\ \text { ('teachers', 'must') } & 167.6654893 & 12030 & 1526 & 48 \\ \text { ('teachers', 'may') } & 163.1856088 & 12030 & 6326 & 84 \\ \text { ('female', 'teachers') } & 148.0626255 & 691 & 12030 & 34 \\ \text { ('how', 'teachers') } & 142.458699 & 7521 & 12030 & 85 \\ \text { ('music', 'teachers') } & 141.1541945 & 839 & 12030 & 35 \\ \text { ('classroom', 'teachers') } & 140.5452037 & 3579 & 12030 & 60 \\ \text { ('teachers', 'perceive') } & 139.4109306 & 12030 & 319 & 26\end{array}$

After labelling the concordances of the selected bigrams, similar labels emerged. The bigrams were clustered into two groups, and two mainstream representations of teacher emerged: teachers are people on whom researchers impose obligations; and "teacherliness" is old and negative.

\section{Teachers are people on whom researchers impose obligations}

The representation that teachers are people on whom researchers impose obligations was derived from the following bigrams: teachers-may; teachers-must; teachers-need; and teachers-should. These four bigrams were clustered together because they shared similar labels. Figure 4 summarises the distribution of labels.

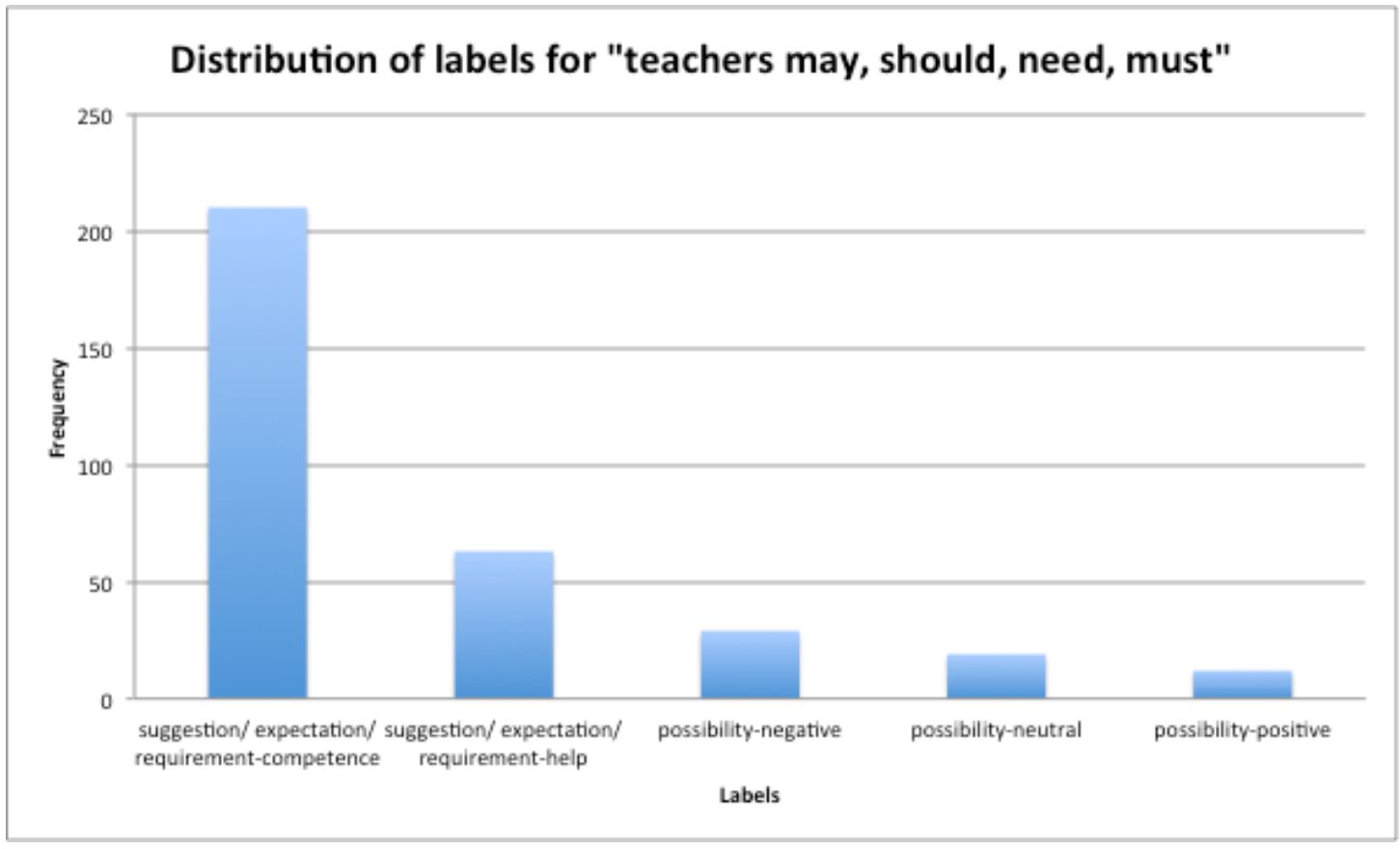

Figure 4. Distribution of labels for "teachers may, should, need, must"

The overwhelming trend from this study is that researchers tend to make demands of teachers regarding competence as a teacher (suggestion/expectation/requirement-competence). Examples of corresponding concordances include:

- today's classroom teachers may need to take on a new role (suggestion-competence)

- all teachers should be computer literate (expectation-competence)

- teachers need to know exactly how IT is to be used (requirement-competence)

- capable teachers must be able to flexibly incorporate new resources including technology (requirement-competence). 
All these verbs (i.e., may, should, need, must) are modal verbs. Therefore, the word teachers has a semantic preference for modal verbs. Modal verbs are linguistic devices that express the author's attitudes towards a particular action (Palmer, 2001). For example, modal verbs can express the author's feelings that an action is possible (some teachers may find new technology a threat), certain (unknowingly, teachers will automatically teach according to their own learning style), or obligatory (teachers need to rethink their approaches).

From the analysis of this corpus, the modal verbs mostly communicate a strong sense of obligation: out of the 210 labels aggregated under "suggestion/expectation/requirement-competence”, 127 were "requirement-competence" (60\%) and 75 were "expectation-competence” (36\%). Therefore, the analysis of this corpus reveals that teachers are typically portrayed as people on whom researchers can and do impose expectations and obligations.

In the corpus, these expectations and obligations typically include teachers' capability to integrate technology (e.g., teachers must engage them in technology-rich learning) and understand the affordances of new technologies (e.g., teachers should be aware of its potential), and their willingness to change (e.g., teachers must be willing to adapt to change) and be open (e.g., teachers must be open to students using their smartphones).

The modal bigram distribution over time suggests an increased incidence of modal bigrams (Figure 5). However, further investigation is required to confirm this. This pattern may simply reflect the increase in journal issues over time, although a similar increase does not occur with other bigrams such as traditional-teachers and traditional-teaching.

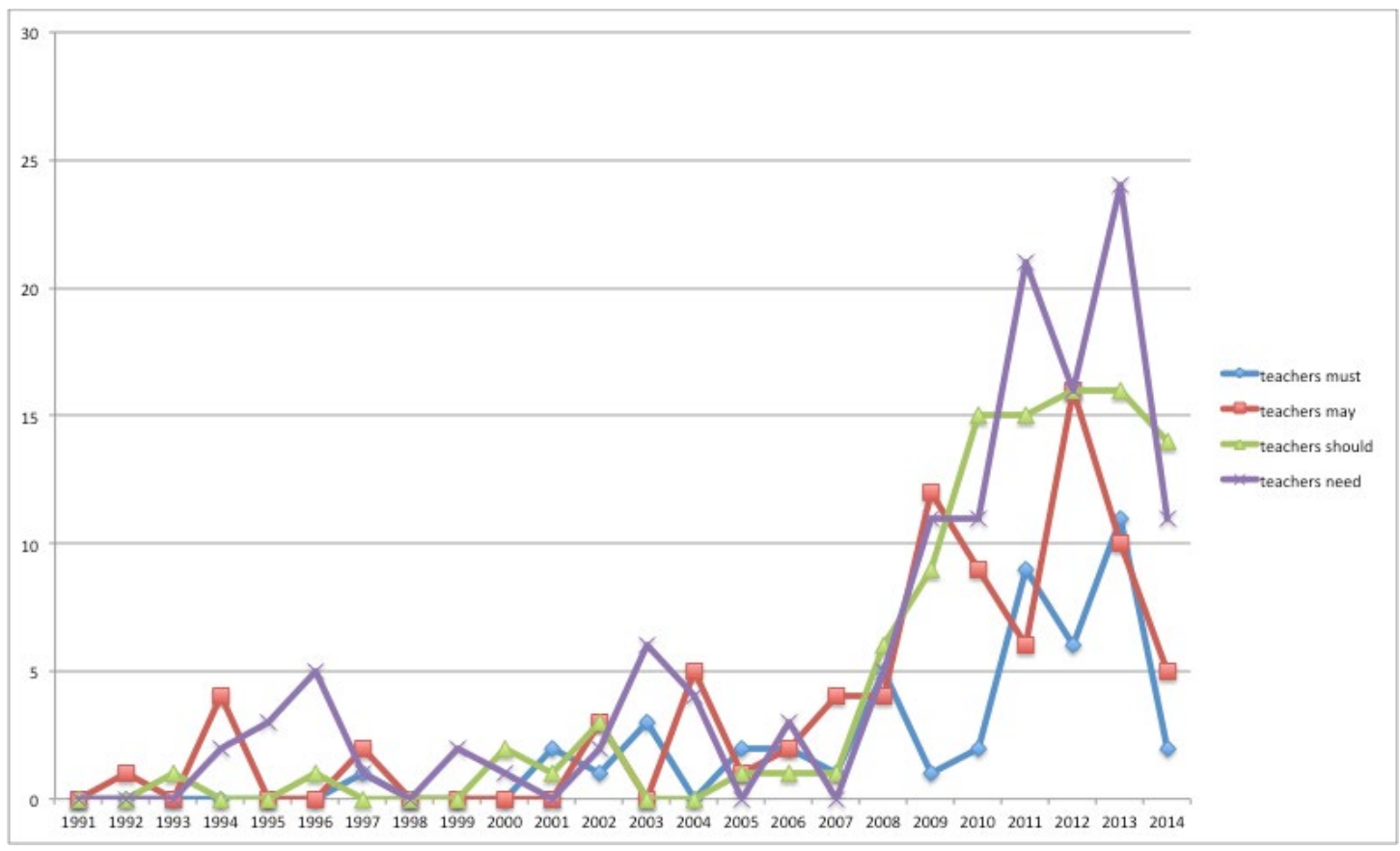

Figure 5. Frequency of modal bigrams over time

The other labels were considerably fewer in number. To provide a fuller picture, here are a few concordances corresponding to the other labels:

- $\quad$ placed emphasis on how teachers should be trained (expectation-help)

- $\quad$ teachers may attempt to apply inappropriate pedagogies (possibility-negative)

- $\quad$ some teachers may embrace ICT wholeheartedly (possibility-positive).

The implications of this finding will be discussed under the Discussion section, in concert with the second representation of teacher. 


\section{Teacherliness is old and negative}

The second representation of teacher is that the quality of being a teacher (henceforth teacherliness) is old and negative. This was derived from the following bigrams: teacher-centred; teacher-directed; traditional-teacher; and traditional-teaching. These four bigrams were clustered together because they shared similar labels. Figure 6 summarises the distribution of labels.

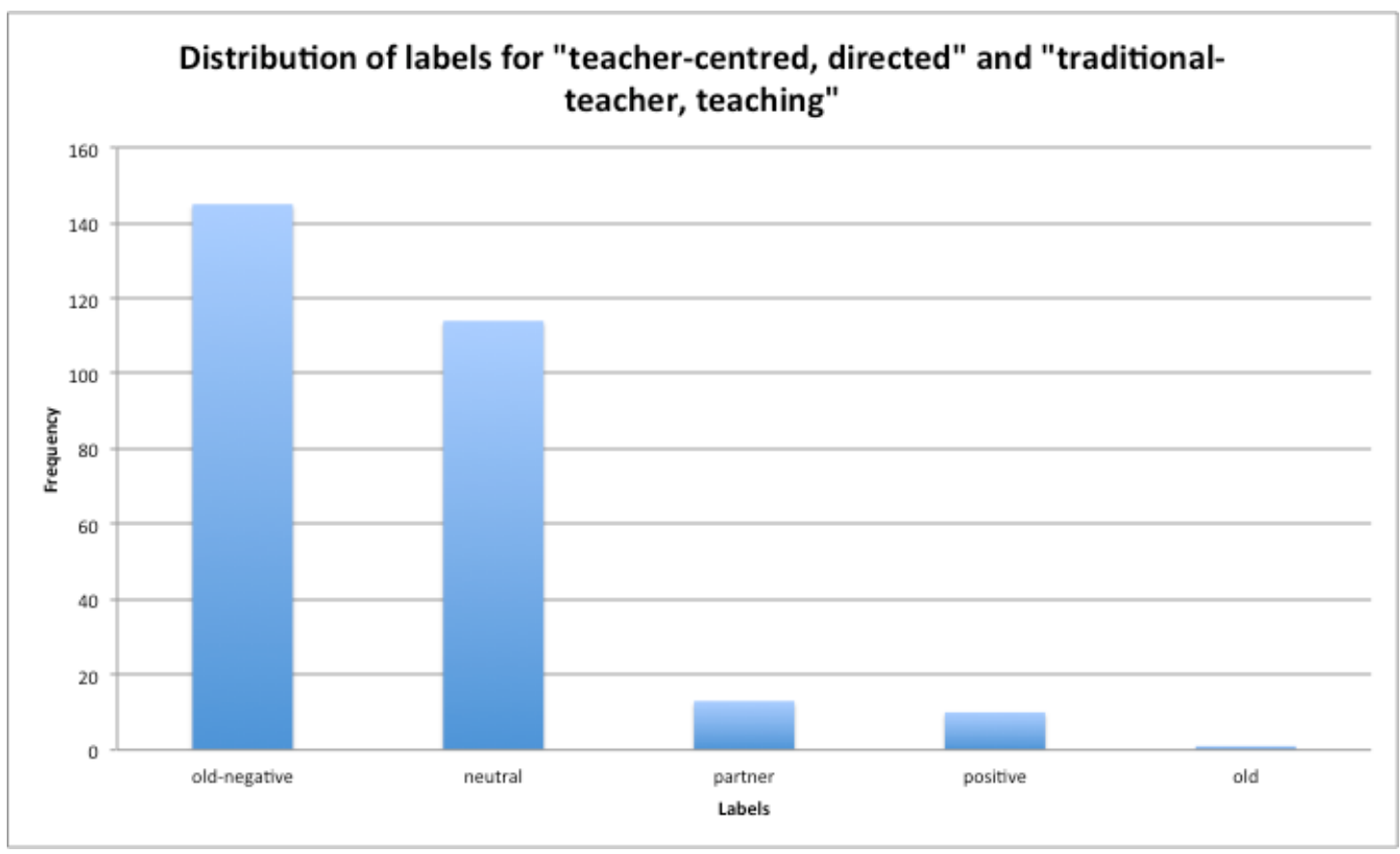

Figure 6. Distribution of labels for "teacher-centred, directed” and "traditional-teacher, teaching”

The main trend from this study is that teacherliness tends to be portrayed as old/obsolete and negative/undesirable (old-negative). Examples of corresponding concordances include:

- help them to rethink traditional teacher centred, didactic instruction (old-negative)

- moving away from a didactic teacher centred model to a more interactive student centred model (old-negative)

- $\quad$ boring and insipid traditional, teacher-fronted classes (old-negative)

- reluctance to change from more traditional teaching methods (old-negative).

The sense of negativity was inferred from two sources. First, researchers often attributed negative characteristics to teacherliness in the corpus, for example, that teacherliness is obsolete, didactic, ineffective, lacking interactivity, or restricting student autonomy. Second, negativity was also signalled by the researchers' aim or recommendation to change from teacherliness, via expressions such as "moving away from", "transition from", and "restructuring learning from". Therefore, the words teacher and teaching have a negative semantic prosody.

The sense of "old" was inferred from the adjective "traditional", the idea that teacherliness is habitual (lessons tended to be teacher directed), and the idea that the starting point of the project involved teacherliness (moved from being teacher centred to becoming student centred).

The second most frequent label was "neutral". Concordances were labelled as "neutral" when teacher(s) and teaching were portrayed neither as positive nor negative (e.g., students $(N=50)$ received a traditional teaching approach) or when positivity or negativity was not clearly communicated (e.g., more likely to be used than uses that are more teacher centred). When in doubt, the authors were cautious and always labelled the concordance as "neutral". This partly explains the high number of "neutral" labels. 
The other three labels were considerably fewer in number. To provide a fuller picture, here are a few concordances corresponding to the other labels:

- $\quad$-learning, when complemented with traditional teaching activities (partner)

- developing a balance between student centred and teacher centred approaches (partner)

- based on the success of implementing teacher centred approaches in their own classrooms (positive).

It is noteworthy that, in labels such as "teacher-centred", "teacher" refers to the quality of being a teacher (teacherliness) and not to any teacher in particular. Even though this is the case, how teacherliness was portrayed in the corpus was examined because this study focuses on researchers' attitudes towards existing teaching and other teacherly practices. Researchers' attitudes towards existing teaching practices are the ones that can impact on how technology integration takes place.

By contrast, any references to aspirational teaching practices will not be discussed. For example, effective-teaching, good-teaching, and innovative-teaching were frequently used bigrams in the corpus that cast teaching in a positive light. However, after an analysis of their use in the corpus, it was found that they referred predominantly to aspirational, idealised teaching principles or models (e.g., Ramsden's (1991) criteria for effective teaching), not to existing teaching practices enacted by teachers. In fact, these "good" teaching principles or models were typically contrasted with existing teaching practices, reinforcing the negativity around existing teaching practices.

The analysis of this corpus indicates that educational technology researchers typically judge teacherliness to be old and negative, and for this reason make demands of teachers to change their current practices or attitudes. From the readers' perspective, what this means is that each time AJET readers read the words teacher(s) or teaching, they are likely to read these words in the senses of being old/obsolete, negative/undesirable or disempowered. In contrast, there were considerably fewer occurrences where teachers, teacherliness, and their existing teaching practices were portrayed as being positive.

\section{Discussion}

First, there are alternative ways to talk about the teaching practices researchers want to move away from without connoting the idea of teacher. To disassociate teacherliness from the current negativity, it is recommended that researchers foreground the aspect or characteristic of the teaching practice they aim to change. For example, researchers can write about such teaching practices as "transmissive teaching" or "memorisation" instead of "teacher-centred teaching".

This recommendation is made because, regardless of how they teach, all teachers inherently engage in the activity of teaching and are expected to perform their duties in a teacherly manner (e.g., in a caring manner). Teachers cannot avoid being called "teachers" (although some have tried by calling themselves "facilitators"); even tertiary lecturers cannot avoid doing the act of "teaching" (and this applies whether they are teaching in a didactic or constructivist way). The portrayal of teacherliness as being old and negative unnecessarily devalues teachers' professional identity and activity.

Second, the portrayal of teacher-centred practices as being negative can be questioned. Even Piaget (1970), an authoritative advocate for constructivist learning who is often cited in educational technology journal papers, recognised the relevance of teacher-centred practices:

Generally speaking, since every discipline must include a certain body of acquired facts as well as the possibility of giving rise to numerous research activities and activities of rediscovery, it is possible to envisage a balance being struck... between the different parts being played by memorising and free activity (p. 78)

In the corpus, teacher-centred practices are cast overwhelmingly in a negative light. The analysis of this corpus reveals only a few mentions of teacher- and student-centred practices being complementary (see the low frequency of "partner" in Figure 6). 
Conversely, the portrayal of student-centred practices as being positive can be questioned. Other researchers have challenged the popular appeal of student-centred approaches: Kirschner, Sweller, and Clark (2006) alerted educators that empirical studies over 50 years indicate that student-centred instruction is less effective and less efficient than teacher-centred instruction; Schweisfurth (2011) that student-centred education might be a Western construct that is irrelevant to non-Western cultures of learning.

In any case, it is recommended that more researchers question the prevailing assumptions that teachercentred practices are necessarily undesirable and that student-centred practices necessarily desirable. Teachers should be able to choose the pedagogy they enact based on its fit for purpose and strike a balance between "memorising and free activity" (Piaget, 1970, p. 78).

Third, the association of negativity with long-established, traditional teaching practices is unnecessary. Educational technology researchers tend to portray new technologies and new pedagogies as being better than the old, "unthinkingly" (Selwyn, 2012, p. 216) associating the new with progress. However, in the education sphere, the old can also be valuable and advantageous: for example, Harvard University brands itself as "the oldest institution of higher education in the United States" (Harvard University, 2016); and the University of Otago as "New Zealand's oldest university" (University of Otago, 2016). It is recommended that researchers be cautious of assuming that the old is necessarily bad and the new necessarily good for education.

Fourth, imposing obligation implies a questionable asymmetry of power between researchers and teachers. Educational technology researchers are expected to make recommendations or give advice to teachers. Examples from the corpus include the authors recommend the construction of IT integration models for Singapore schools (making recommendations) and we advise to implement learner pacing for multimedia instructions (giving advice). However, the acts of recommending and advising do not necessarily imply imposing obligation on teachers. What was typically found in the corpus is that researchers define how teachers ought to be/act (e.g., teachers should harness this multimodality of the $I W B$ ) and somehow wield the power to impose those expectations on teachers.

One possible explanation of this imposition of expectations is the tendency for educational technology researchers to over-sell new technologies and pedagogies to teachers. Selwyn (2012) lamented that the educational technology community "has long been an area full of 'hucksters,' evangelists, consultants and visionaries who are keen to tout their personal interpretations of what technology can 'do' for education" (p. 214). Overselling is typically mediated by strong language. Nevertheless, regardless of the explanation, the authors wish to highlight the potential implications of such a sense of obligation.

The implicit power dynamics between researchers and teachers should be questioned. In certain cases, where the researcher is a manager of teachers, for example, the asymmetry of power is legitimised by the educational institution. In other cases, where the researcher is an academic developer, for example, the basis of this asymmetry is less straightforward. Manathunga (2007) highlights the potential dishonesty and tension when academic developers are "positioned as the [more powerful] developer of Others, especially Others who may have had so much more experience of academic work" (p. 27). It is possible that many educational technology researchers who are academic developers in their institution do encounter this tension.

Academic developers can position themselves in other ways. Land (2001) describes how academic developers can conduct their work along a continuum tending either towards "domesticating" (focusing on achieving institutional goals) or "emancipatory" purposes (focusing on teachers' personal growth and choice) (p. 4). The corpus analysis presented here indicates that educational technology researchers tend to adopt the "domesticating" orientation, positioning the proposed change in teaching practice as being expected or obligatory. This is likely to result in the disempowerment of teachers (Friesen, 2008), which in turn is likely to lower teacher buy-in, an important factor in technology integration (Lynch, 2002). Mandating technology use has also been shown to be negatively correlated with teacher competence in using technology (Yeung, Taylor, Hui, Lam-Chiang, \& Low, 2011). For these reasons, it is recommended that researchers adopt a more collegial stance when giving advice to teachers. 
This last recommendation is also made so that researchers avoid committing a potential internal contradiction. In the corpus, most researchers advocate for student-centred learning, in the name of student choice and student autonomy. However, the way researchers themselves impose obligations on teachers signals the opposite, that they accept the restriction of teacher choice and teacher autonomy. Internal consistency is key to carry out research and academic development work with integrity.

\section{Limitations}

This study has several limitations: First, only one journal was studied. Nonetheless, there is no compelling reason to believe that teacher would be represented very differently in other reputable educational technology journals since AJET is widely read and well regarded internationally. As such, a study of one journal should suffice to answer the study's research questions, although the authors hope to extend their future work with other journals to provide a more nuanced picture.

Second, the study's findings were derived from sparse data. For example, while teacher-centred was one of the top 30 bigrams, it occurred only 133 times in a corpus of over 5 million words. However, such is the nature of authentic language use in a large sample space.

Third, only contiguous bigrams were studied (i.e., one word to the left and one to the right of teacher(s) and teaching). An extension to study non-contiguous bigrams (e.g., teaching staff must, teaching assistants must, teaching duties must) would likely give a fuller picture, but would also increase the complexity of undertaking this study.

\section{Conclusions}

This study sought to examine the discursive constructions of teacher in an educational technology journal. The findings are that educational technology researchers typically judge teacherliness to be old and negative, and for this reason make demands of teachers to change their current practices or attitudes.

Corpus studies are particularly suitable for revealing the "preexisting cultural codes” (McKernan, 2013, p. 311) of a specific community. Through this study, some of the pre-existing and implicit cultural codes of the AJET educational technology community were made explicit. As such, new members to the community would do well to understand that shifting away from teacher-centred instruction, judged to be obsolete and undesirable, forms one of the community's dominant narratives. Existing members can now be more conscious about whether they want to perpetuate these cultural codes.

Broadly, these mainstream representations of teacher are likely to accentuate the negativity around teacher in the current climate where new technologies are seen to be competing against teachers and where teaching is arguably less valued than research. For the reasons given above, perpetuating this negativity is unlikely to facilitate meaningful and sustained technology integration. It is recommended that researchers allow teachers to choose which (if any) technology to adopt in their classes (Loke, 2013) and also adopt a more nuanced attitude towards the negativity of teacher-centred approaches.

\section{References}

ÅKerlind, G. S. (2003). Growing and developing as a university teacher: Variation in meaning. Studies in Higher Education, 28(4), 375-390. doi:10.1080/0307507032000122242

Andor, J. (2004). The master and his performance: An interview with Noam Chomsky. Intercultural Pragmatics, 1(1), 93-111. doi:10.1515/iprg.2004.009

Anthony, L. (2014). AntConc (Version 3.4.3) [Computer Software]. Tokyo: Waseda University. Retrieved from http://www.laurenceanthony.net/

ascilite. (2015). Australasian Journal of Educational Technology. Retrieved from http://ascilite.org.au/ajet/submission/index.php/AJET/index

Bali, M. (2014). MOOC pedagogy: Gleaning good practice from existing MOOCs. MERLOT Journal of Online Learning and Teaching, 10(1), 44-56. Retrieved from http://jolt.merlot.org/vol10no1/bali_0314.pdf 
Baylor, A. L., \& Ritchie, D. (2002). What factors facilitate teacher skill, teacher morale, and perceived student learning in technology-using classrooms? Computers \& Education, 39(4), 395-414. doi:10.1016/S0360-1315(02)00075-1

Bennett, S., Maton, K., \& Kervin, L. (2008). The “digital natives” debate: A critical review of the evidence. British Journal of Educational Technology, 39(5), 775-786. doi:10.1111/j.14678535.2007.00793.x

Biber, D., Conrad, S., \& Reppen, R. (1998). Corpus linguistics: Investigating language structure and use. New York, NY: Cambridge University Press.

Bird, S., Loper, E., \& Klein, E. (2009). Natural language processing with Python. Sebastopol, CA: O’Reilly Media Inc.

British Educational Research Association. (2015). British Journal of Educational Technology. Retrieved from http://onlinelibrary.wiley.com/journal/10.1111/\%28ISSN\%2914678535/homepage/ProductInformation.html

Cadez, S., Dimovski, V., \& Zaman Groff, M. (2015). Research, teaching and performance evaluation in academia: The salience of quality. Studies in Higher Education. doi:10.1080/03075079.2015.1104659

Chalmers, D. (2011). Progress and challenges to the recognition and reward of the scholarship of teaching in higher education. Higher Education Research \& Development, 30(1), 25-38. doi:10.1080/07294360.2011.536970

Clark, R. E. (1994). Media will never influence learning. Educational Technology Research and Development, 42(2), 21-29. doi:10.1007/BF02299088

Clegg, S., Hudson, A., \& Steel, J. (2003). The emperor's new clothes: Globalisation and e-learning in higher education. British Journal of Sociology of Education, 24(1), 39-53. doi:10.1080/01425690301914

Cochran-Smith, M. (2003). The multiple meanings of multicultural teacher education: A conceptual framework. Teacher Education Quarterly, 30(2), 7-26. Retrieved from http://www.jstor.org/stable/23478466

Curtis, B., \& Matthewman, S. (2005). The managed university: The PBRF, its impacts and staff attitudes. New Zealand Journal of Employment Relations, 30(2), 1-18. Retrieved from http://www.nzjournal.org/NZJER30(2).pdf

Deakin University. (2016). CloudDeakin guides. Retrieved from http://www.deakin.edu.au/learning/cloud-learning/clouddeakin/guides

Ertmer, P. A., Ottenbreit-Leftwich, A. T., Sadik, O., Sendurur, E., \& Sendurur, P. (2012). Teacher beliefs and technology integration practices: A critical relationship. Computers \& Education, 59(2), 423-435. doi:10.1016/j.compedu.2012.02.001

Friesen, N. (2008). Critical theory: Ideology critique and the myths of e-learning. ACM Ubiquity, 9(22). Retrieved from http://ubiquity.acm.org/article.cfm?id=1386860

Hanson, J. (2009). Displaced but not replaced: The impact of e-learning on academic identities in higher education. Teaching in Higher Education, 14(5), 553-564. doi:10.1080/13562510903186774

Harrison, L. M., \& Risler, L. (2015). The role consumerism plays in student learning. Active Learning in Higher Education, 16(1), 67-76. doi:10.1177/1469787415573356

Harvard University. (2016). About Harvard. Retrieved from http://www.harvard.edu/about-harvard

Hyland, K. (2004). Disciplinary discourses: Social interactions in academic writing (Michigan Classics Ed.). Ann Arbor: University of Michigan Press.

Kennedy, G. E., Judd, T. S., Churchward, A., Gray, K., \& Krause, K. L. (2008). First year students' experiences with technology: Are they really digital natives? Australasian Journal of Educational Technology, 24(1), 108-122. doi:10.14742/ajet.1233

Kirschner, P. A., Sweller, J., \& Clark, R. E. (2006). Why minimal guidance during instruction does not work: An analysis of the failure of constructivist, discovery, problem-based, experiential, and inquirybased teaching. Educational Psychologist, 41(2), 75-86. doi:10.1207/s15326985ep4102_1

Kirschner, P. A., \& van Merriënboer, J. J. G. (2013). Do learners really know best? Urban legends in education. Educational Psychologist, 48(3), 169-183. doi:10.1080/00461520.2013.804395

Kovanović, V., Joksimović, S., Gašević, D., Siemens, G., \& Hatala, M. (2015). What public media reveals about MOOCs: A systematic analysis of news reports. British Journal of Educational Technology, 46(3), 510-527. doi:10.1111/bjet.12277

Kozma, R. B. (1994). Will media influence learning? Reframing the debate. Educational Technology Research and Development, 42(2), 7-19. doi:10.1007/BF02299087

Lakoff, G., \& Johnson, M. (1980). Metaphors we live by. Chicago, IL: University of Chicago Press. 
Land, R. (2001). Agency, context and change in academic development. International Journal for Academic Development, 6(1), 4-20. doi:10.1080/13601440110033715

Landis, J. R., \& Koch, G. G. (1977). The measurement of observer agreement for categorical data. Biometrics, 33(1), 159-174. Retrieved from http://www.jstor.org/stable/2529310

Lee, A., \& Green, B. (2009). Supervision as metaphor. Studies in Higher Education, 34(6), 615-630. doi:10.1080/03075070802597168

Lewis, J. (2013, July 10). Uni teaching underrated, lecturer says. Otago Daily Times. Retrieved from http://www.odt.co.nz/campus/university-otago/264225/uni-teaching-underrated-lecturer-says

Loke, S.-K. (2013). Framed by technology. British Journal of Educational Technology, 44(2), E49-E51. doi:10.1111/j.1467-8535.2012.01329.x

Louw, B., \& Chateau, C. (2010). Semantic prosody for the 21st century: Are prosodies smoothed in academic context? A contextual prosodic theoretical perspective. In S. Bolasco, I. Chiara, \& L. Giuliano (Eds.), Proceedings of the International Conference on the Statistical Analysis of Textual Data (JADT ) (pp. 754-764). Milan: LED Edizioni Universitarie di Lettere Economie Diritto.

Lynch, M. M. (2002). The online educator: A guide to creating the virtual classroom. London: Routledge.

Manathunga, C. (2007). "Unhomely” academic developer identities: More post-colonial explorations. International Journal for Academic Development, 12(1), 25-34. doi:10.1080/13601440701217287

Manning, C., \& Schütze, H. (1999). Foundations of statistical natural language processing. Cambridge, MA: MIT Press.

McEnery, T., \& Hardie, H. (2011). Corpus linguistics: Method, theory and practice. New York, NY: Cambridge University Press.

McEnery, T., Xiao, R., \& Tono, Y. (2006). Corpus-based language studies: An advanced resource book. Oxfordshire: Taylor \& Francis.

McKernan, B. (2013). The morality of play: Video game coverage in The New York Times from 1980 to 2010. Games and Culture, 8(5), 307-329. doi:10.1177/1555412013493133

Melenyzer, B. J. (1990, November). Teacher empowerment: The discourse, meanings and social actions of teachers. Paper presented at the Annual Conference of the National Council of States on Inservice Education, Orlando, Florida.

Oster, U. (2010). Using corpus methodology for semantic and pragmatic analyses: What can corpora tell us about linguistic expression of emotions? Cognitive Linguistics, 21(4), 727-763. doi:10.1515/cogl.2010.023

Palmer, F. R. (Ed.) (1968). Selected papers of J. R. Firth 1952-59. London: Longmans.

Palmer, F. R. (2001). Mood and modality (2nd ed.). Cambridge: Cambridge University Press.

Peck, K. (2013, March 12). The evolving role of "teacher" in a MOOCs and badges world. The EvoLLLution. Retrieved from http://www.evolllution.com/opinions/role-teacher-moocs-badges-world/

Piaget, J. (1970). Science of education and the psychology of the child. New York, NY: Orion Press.

Prensky, M. (2001). Digital natives, digital immigrants. On the Horizon, 9(5), 1-6. doi:10.1108/10748120110424816

Prosser, M., Trigwell, K., \& Taylor, P. (1994). A phenomenographic study of academics' conceptions of science learning and teaching. Learning and Instruction, 4(3), 217-231. doi:10.1016/09594752(94)90024-8

$\mathrm{R}$ Core Team. (2015). R: A language and environment for statistical computing. Vienna: R Foundation for Statistical Computing. Retrieved from http://www.R-project.org/

Ramsden, P. (1991). A performance indicator of teaching quality in higher education: The course experience questionnaire. Studies in Higher Education, 16(2), 129-150. doi:10.1080/03075079112331382944

Reiser, R. A. (2001). A history of instructional design and technology: Part I: A history of instructional media. Educational Technology Research and Development, 49(1), 53-64. doi:10.1007/BF02504506

Rowland, S. (1996). Relationships between teaching and research. Teaching in Higher Education, 1(1), 7-20. doi:10.1080/1356251960010102

Schaffner, A. C. (1994). The future of scientific journals: Lessons from the past. Information Technology and Libraries, 13(4), 239-247.

Schweisfurth, M. (2011). Learner-centred education in developing country contexts: From solution to problem? International Journal of Educational Development, 31(5), 425-432. doi:10.1016/j.ijedudev.2011.03.005

Selwyn, N. (2012). Ten suggestions for improving academic research in education and technology. Learning, Media and Technology, 37(3), 213-219. doi:10.1080/17439884.2012.680213 
University of Otago. (2016). Our history. Retrieved from http://www.otago.ac.nz/about/history/

Vannatta, R. A., \& Nancy, F. (2004). Teacher dispositions as predictors of classroom technology use. Journal of Research on Technology in Education, 36(3), 253-271. doi:10.1080/15391523.2004.10782415

Victoria University. (2016). Digital vision. Retrieved from http://www.victoria.ac.nz/learningteaching/academic-development/digital-vision

Xiao, R., \& McEnery, T. (2006). Collocation, semantic prosody, and near synonymy: A cross-linguistic perspective. Applied Linguistics, 27(1), 103-129. doi:10.1093/applin/ami045

Yeung, A. S., Taylor, P. G., Hui, C., Lam-Chiang, A. C., \& Low, E.-L. (2011). Mandatory use of technology in teaching: Who cares and so what? British Journal of Educational Technology, 43(6), 859-870. doi:10.1111/j.1467-8535.2011.01253.x

Young, P. (2006). Out of balance: lecturers' perceptions of differential status and rewards in relation to teaching and research. Teaching in Higher Education, 11(2), 191-202. doi:10.1080/13562510500527727

Zhu, C., Valcke, M., \& Schellens, T. (2010). A cross-cultural study of teacher perspectives on teacher roles and adoption of online collaborative learning in higher education. European Journal of Teacher Education, 33(2), 147-165. doi:10.1080/02619761003631849

Corresponding author: Jenny McDonald, jenny.mcdonald@otago.ac.nz

Australasian Journal of Educational Technology (C) 2016.

Please cite as: McDonald, J., \& Loke, S.-K. (2016). Discursive constructions of teacher in an educational technology journal. Australasian Journal of Educational Technology, 32(5), 77-93.

https://doi.org/10.14742/ajet.2787 